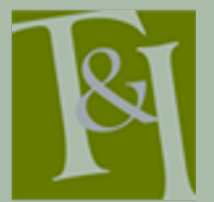

The International Journal for Translation \& Interpreting Research trans-int.org

\section{A survey of Korean elementary schoolteachers on their communication with students and parents from migrant backgrounds and the need for quality language services}

\author{
Jieun Lee \\ Ewha Womans University, Republic of Korea \\ jieun.lee@ewha.ac.kr
}

DOI: 10.12807/ti.113201.2021.a07

\begin{abstract}
This paper investigates communication problems facing teachers when they interact with students and parents from migrant backgrounds, and explores the need for quality language services in educational settings. According to a questionnaire-based survey of 142 elementary schoolteachers, about 20-25 per cent of respondents frequently experienced difficulties in communicating with students and parents who lacked Korean language proficiency. However, the teachers usually managed without outside assistance largely because of the lack of language support services. Effective communication is needed through the delivery of more language services to support children's learning, school education and parents' meaningful participation in both. Most teachers surveyed supported more effective language services in their schools, but were not very vocal in advocating for professional interpreting services. Instead, they tended to emphasise other forms of language and cultural training for multicultural students and their parents. This response may derive from their lack of experience with professional interpreting services, and a lack of awareness of the limited resources available for quality service provision or the influence of assimilation policies. The findings also indicate that teachers do not consider the interpreting and translation skills of language service providers as highly as cross-cultural mediation skills, understanding of the education system or interest in individual students' needs. The results call for further research into what would constitute best practice in educational interpreting to effectively mediate cultural differences between schools and multicultural families, and address the needs and concerns of teachers, students and parents from multicultural backgrounds.
\end{abstract}

Keywords: multicultural students; migrant parents; elementary schoolteachers; language services; educational interpreting; cross-cultural mediation

\section{Introduction}

The number of migrants in South Korea is small compared to countries such as the United States, Canada and Australia. ${ }^{1}$ However, the demographic changes sparked by large-scale inter-Asian migration, and especially the increasing

${ }^{1}$ In 2017, 3.4\% of the South Korean population were foreign residents (Ministry of Interior and Safety, 2017).

Translation \& Interpreting Vol. 13 No. 1 (2021) 
number of female marriage migrants, have posed unprecedented challenges to sociocultural cohesion. The enactment of the 2007 Framework Act on the Treatment of Foreigners Residing in the Republic of Korea was the start of several policies and programs implemented by the Korean government to support the settlement of marriage migrants and multicultural families. In South Korea, 'multicultural families' primarily comprise international marriages between Korean men and female migrants mostly from other Asian backgrounds (Kim, 2008; Yang, 2013). Despite a decreasing school-age population resulting from a falling birth rate, the number of multicultural students or school-age children of the so-called multicultural families has risen (Nam \& Kim, 2012, p. 114). Most of these children are elementary school students (aged 7-12) whose enrolment has increased 2.5-fold in five years, from 33,740 in 2012 to 82,733 in 2017 (Ministry of Education [MOE], 2017). Since the educational needs of multicultural students are obvious (i.e., they are often from lower to middle socio-economic backgrounds), there is a consensus that systematic support is needed to build these students' learning abilities so they can fully participate in school life.

During the early years of elementary school, parents tend to play a larger role in their children's school education than they do in later schooling years (Kim \& Lee, 2016; J. B. Lee et al., 2009). To participate in their children's education and support their schooling, parents need to be able communicate with schoolteachers without difficulty. Communication between teachers and parents affects a child's development and ability to integrate both at school and in the community (Davitti, 2013, p. 175). Given that both home and school play a vital role in education (Sanders \& Epstein, 2000; Xu \& Gulosino, 2006), it is imperative for teachers and parents to work in partnership, exchanging information and ideas and sharing responsibility for a child's growth, development and education. In this partnership, communication is essential to building trust and cooperation between teachers and parents. This paper examines this issue of communicative needs in elementary school education from the perspective of interpreting studies.

Various factors, such as the length of residence, family support and individual inclination, affect the overall school performance of multicultural students. In the South Korean context, mothers are more closely involved in their children's education, while migrant mothers' lack of Korean language proficiency is a challenging factor in the education of their school-age children. Thus, because these multicultural students are usually nurtured and raised by migrant mothers with insufficient Korean language proficiency, they often lack the literacy and language skills required for schooling, leading to poor educational achievement and behavioural problems (Cheon \& Park, 2012; Choi \& Hwang, 2009; Hwang et al., 2010). Lack of Korean language proficiency is one of the three major reasons cited for multicultural students' difficulty in adapting to school life, following peer relationship problems and a lack of interest in their studies (Chung et al., 2016).

Children may fall behind peers and struggle with schoolwork if they do not receive proper support from their parents during the early school years. Unfortunately, many migrant mothers face difficulties in helping with children's schooling because of linguistic, socio-economic and cultural differences (J. B. Lee et al., 2009; Nam \& Kim, 2012). Migrant mothers from low and middle socio-economic backgrounds often have difficulty in homeschool communication and participating in their children's school education (Bae \& Suh, 2013; Han \& Kim, 2011). For these same reasons, they may avoid visiting their children's school or attending school events (Nam \& Kim, 2012). 
Moreover, migrant mothers' communication with teachers and other parents tends to be minimal because they cannot have a meaningful dialogue due to their limited language proficiency (Chung et al. 2016, pp. 116-117).

Although it may take time for migrants to speak Korean with enough fluency to discuss their children's schooling with teachers, the focus of migrant support programs has been on developing Korean language skills and learning about Korean culture and society. The need for quality language services that would rapidly enhance the ability of migrant parents to communicate with public service providers, including schoolteachers, has been largely overlooked. Despite the growing number of migrants, there is a lack of professional language services available throughout the public service sector (J. Lee et al., $2014 \mathrm{~b}, 2015)$. This could be related to the low socio-economic backgrounds of many migrants by marriage, who are expected to quickly learn Korean and adapt to Korean society. The situation also reflects the language policy and ideology behind a range of Korean multicultural policies that lean towards integration based on assimilation and acculturation (Kang, 2013; Lee \& Kim, 2016). Existing research has focused primarily on the importance of Korean language education, which has largely overlooked the pressing need for facilitating communication between home and school and within school. This paper seeks to address the issue of communication between elementary schoolteachers, migrant parents and multicultural students. It advocates for quality language services to facilitate communication in educational settings that would ultimately support the education of students from diverse cultural and linguistic backgrounds.

\section{Educational interpreting}

Community interpreting can enhance the clarity of communication and rapport building between respondents in diverse settings, including education. Quality interpreting is a critical factor in ensuring equal opportunity and fair access to education regardless of the users' cultural, linguistic or ethnic background. Community interpreting in education settings is often referred to as educational interpreting, which is essential in various settings where learning takes place. For the purposes of this paper educational interpreting refers to spoken language interpreting in elementary school education settings where instructional activities occur inside and outside the classroom, such as counselling, parentteacher discussions and school events.

Despite government interest in supporting multicultural students who lack Korean language proficiency, there is a lack of quality language services to support their learning during the critical transition period. The literature on multicultural students' education in the South Korean context largely focuses on special assistance programs, and there is limited mention of interpreting services. For example, Park (2011) suggested introducing an assistant teacher program to provide language assistance to multicultural students during class. ${ }^{2}$ Park (2011, p. 116) noted that to adequately perform such a role, linguistic skills and curriculum knowledge are essential.

\footnotetext{
${ }^{2}$ Assistant teachers are recruited from teacher trainees in teachers' colleges, and they assist students with special needs during class hours. However, multicultural students with limited Korean proficiency are not eligible recipients of the current assistant teacher programs (Park, 2011).
} 
While the MOE does not offer language services for multicultural students, the Ministry of Gender Equality and Family-funded Multicultural Family Support Centres (MFSCs) offer language services for marriage migrants and their families (J. Lee et al., 2016). The bilingual staff, who are themselves marriage migrant women, provide interpreting and translation services in a wide range of community settings. Thirty per cent of the MFSC translation and interpreting services is related to education, highlighting that language services are needed in educational settings (J. Lee et al., 2014a, p. 183). Unfortunately, not all language needs are met because of limited resources. Typical local MFSCs employ between one and three interpreters from the highest demand languages in the region. Since little is known about the current state of educational interpreting, it is not known whether educational interpreting needs are fulfilled from the perspective of teachers. Further, because language service providers from migrant backgrounds are not professionally trained interpreters and translators, the service quality is often a controversial issue (J. Lee et al., 2016). A recent survey of speech development therapists often working for multicultural students through the assistance of MFSC interpreters revealed that common complaints are lack of service availability and interpreting skills (Hwang, 2019).

Fulfilling educational interpreting needs is difficult, as teacher-parent communication is not a simple conversation limited only to the transmission of information. Meaningful interactions between teachers and parents may involve actively seeking solutions, sharing knowledge and resources (Davitti, 2013, p. 173). This is not easily achieved in teacher-parent talks in the same language and may be more challenging between teachers and parents from different cultural and linguistic backgrounds. Such talks may involve questions into the private sphere of family life or problem-solving concerning a child's attitude, academic performance and relationship with peers or teachers (Adelsward \& Nilholm ,1998; Leung \& Yeun, 2001). To navigate such topics given these language barriers, professional assistance is needed for effective communication. Mediating cross-linguistic and cross-cultural communication in an educational context requires not only bilingual and bicultural fluency but also sensitivity, delicacy, tactfulness and psychological and emotional involvement (Rudvin \& Tomassini, 2008, p. 54).

This is why ad-hoc interpreting is inadequate and insufficient but not uncommon in education settings. Even children are sometimes expected to bridge the linguistic gap. Children of migrant families often interpret for their parents or others who do not speak the language of the host country. This type of informal interpreting is called 'language brokering' (Hall, 2004; Morales \& Hanson, 2005), and is considered inappropriate in the community interpreting literature given that children should not be expected to interpret sensitive or confidential information that is inappropriate for their age (Ragavan and Cowden, 2018; Shackman, 1984; Victorian Government, n.d.).

However, children's language brokering in an educational context has attracted scholarly attention chiefly because of its positive effects on children's educational and social development (Angelelli, 2010; Borrero, 2011; Bullock \& Harris, 1997; Buriel et al., 1998; Tse, 1995). Nevertheless, language brokering by young students, who are untrained non-professionals, certainly has its limitations, and the experience may have negative emotional effects on young migrant language brokers (Morales \& Hanson, 2005; McQuillan \& Tse, 1995; Ng, 1998; Weisskirch \& Alva-Alatorre, 2002).

Although there has been a lack of discussion on best practices in educational interpreting, skill requirement, and training, it may be argued that 
interpreting for students and parents with limited proficiency in the language of instruction can be part of many learning support mechanisms (Tipton \& Furmanek, 2016, p. 166). As such, interpreters in educational settings have a crucial role in ensuring the meaningful participation of children from diverse cultural and linguistic backgrounds in school education, as well as their empowerment and social integration. For these purposes, more active mediation by the interpreter is discussed in the literature. This type of mediation, termed 'transformative mediation' (Bush \& Folger, 1994), requires interpreters to assist respondents' self-expression and effective communication by ensuring their active participation while maintaining sensitivity for their interests and needs (Baraldi, 2009; Hlavac, 2017).

Few discourse-based studies have analysed the application of various forms of mediation in educational settings (e.g., Davitti, 2013; Hlavac, 2017; Vargas-Urpi, 2015). These studies demonstrate that interpreter mediation strategies, such as making additional comments, inquiries and selective interpreting, are not always conducive to transformative mediation, and often fail to achieve partnership through empowerment of the parents (Davitti, 2013). Although interpreters attempt to advocate for the migrant during the interpreted event, they may not empower the migrants effectively through editing or selective interpreting because it would deprive the migrants of opportunities to talk for themselves (Vargas-Urpi, 2015). Hlavac (2017) focused on a case of effective mediation by a bilingual teacher. She shifted her roles between faithfully transmitting and facilitating communication to prevent communication breakdown, drawing on her understanding of the intentions and purposes of the communicative event from the teacher perspective. These studies analysed interpreting and mediation using a heterogeneous group of interpreters (i.e., professional interpreters, ad-hoc interpreters and cultural mediators) and did not distinguish interpreting from mediation. Therefore, it is not easy to infer from the existing literature what best practice in educational interpreting might entail, nor what the range of appropriate mediation for educational interpreters might comprise and other professional ethics-related issues. Obviously, there is no single recommendation that can be applied across the board, and further research is needed to investigate effective educational interpreting skills and good practices. However, the communicative needs of all parties involved in education should be first identified. This paper focuses on teachers' experiences and perspectives.

\section{The study}

This study aimed to examine (1) Korean elementary schoolteachers' communication experiences with multicultural students and their migrant parents from non-Korean-speaking backgrounds and (2) teachers' perspectives on communication difficulties and the need for community language services.

\subsection{Methodology}

In April 2017, a letter was emailed to 380 elementary school vice principals in Busan inviting them to participate in an online survey. ${ }^{3}$ The letter contained information about the research, a website link to the survey, as well as an

\footnotetext{
${ }^{3}$ Busan is the second largest city in South Korea, where 1.7 per cent of elementary school students are from multicultural family backgrounds (Hwang, 2016).
} 
invitation to share the link with other teachers willing to participate. The survey comprised 34 multiple-choice questions and one open-ended question for comments and suggestions. The questions sought information on respondents' demographic profile, teaching experiences, experiences of teaching multicultural students, communication with multicultural students and their parents and associated challenges. It also asked about frequently used modes of communication and respondents' experiences of using third party assistance, including external language services. Finally, respondents were asked to provide general comments and suggestions about the communication issues and ways to improve the situation. While this survey asked about teachers' communication with multicultural students and their parents, its primary focus was on teachers' interactions with migrant parents. The data collection took a little over two weeks.

\subsection{Respondents and their teaching experience}

Of the 147 teachers who completed the survey, 142 had taught multicultural students and these 142 responses were analysed for this study. Most respondents were women $(75.4 \%) .{ }^{4}$ The largest number of respondents were in their fifties $(44.4 \%)$ followed by those in their forties $(29.6 \%)$. The third largest group were in their thirties $(21.1 \%)$, while the smallest group was in their twenties $(4.9 \%)$. Most respondents $(\mathrm{n}=119 ; 83.3 \%)$ had had over 10 years of teaching experience, and $73(61.3 \%)$ had over 20 years' experience.

The respondents had experience in teaching multicultural students as homeroom teachers or multicultural affairs teachers. ${ }^{5}$ Approximately 80 per cent of respondents had been or were currently homeroom teachers of multicultural students at the time of the survey, while a little over 30 per cent of respondents had served as or were currently working as multicultural affairs teachers.

Most respondents (73.2\%) had taught multicultural students for one to four years, 11.3 per cent had taught them for five to nine years and 14.1 per cent had taught them for less than one year. Only 1.4 per cent of respondents had taught multicultural students for over 10 years. The results indicated that an overwhelming majority of respondents had started teaching multicultural students only recently. Further, the number of multicultural students they had taught over the preceding five years was small. Seventy-six per cent had taught one to five students, 16.2 per cent had taught six to 10 students while only 7.7 per cent had taught over 10 multicultural students. Thus, the relatively limited exposure to multicultural students might have influenced the teachers' attitude towards the issue of cross-linguistic and cross-cultural communication.

\subsubsection{Teachers' experience of communication with multicultural students}

To assess the extent to which teachers experienced communication difficulties, they were asked how often they had experienced communication difficulties with multicultural students. Little difference was found between communication in and outside class. On average, roughly 20 per cent of respondents experienced communication problems frequently or very frequently, nearly 60 per cent experienced difficulties rarely or very rarely and

\footnotetext{
${ }^{4}$ Women comprise 77 per cent of elementary schoolteachers in South Korea, and the average age of elementary schoolteachers in Korea is 40 (MOE, 2017).

${ }^{5}$ The term 'multicultural affair teacher' refers to a teacher in charge of the multicultural affairs of their respective school. Their role may vary from school to school. Specialist training is not required for this role.
} 
about 20 per cent remained neutral (see Figure 1). The low percentage of teachers experiencing communication difficulties might be due to the small number of multicultural students they had taught. This became clear when examining the responses of teachers with more exposure to multicultural students, as these teachers experienced communication problems more frequently than those who did not. However, the sample size of eight was too small to verify statistical significance. Of the eight teachers who had taught 16 or more multicultural students, five had experienced communication problems frequently or very frequently in class and four had such problems frequently or very frequently outside class. By contrast, the 28 teachers who reported little difficulty in communicating with multicultural students had less experience teaching multicultural students and fewer students with very limited Korean proficiency.

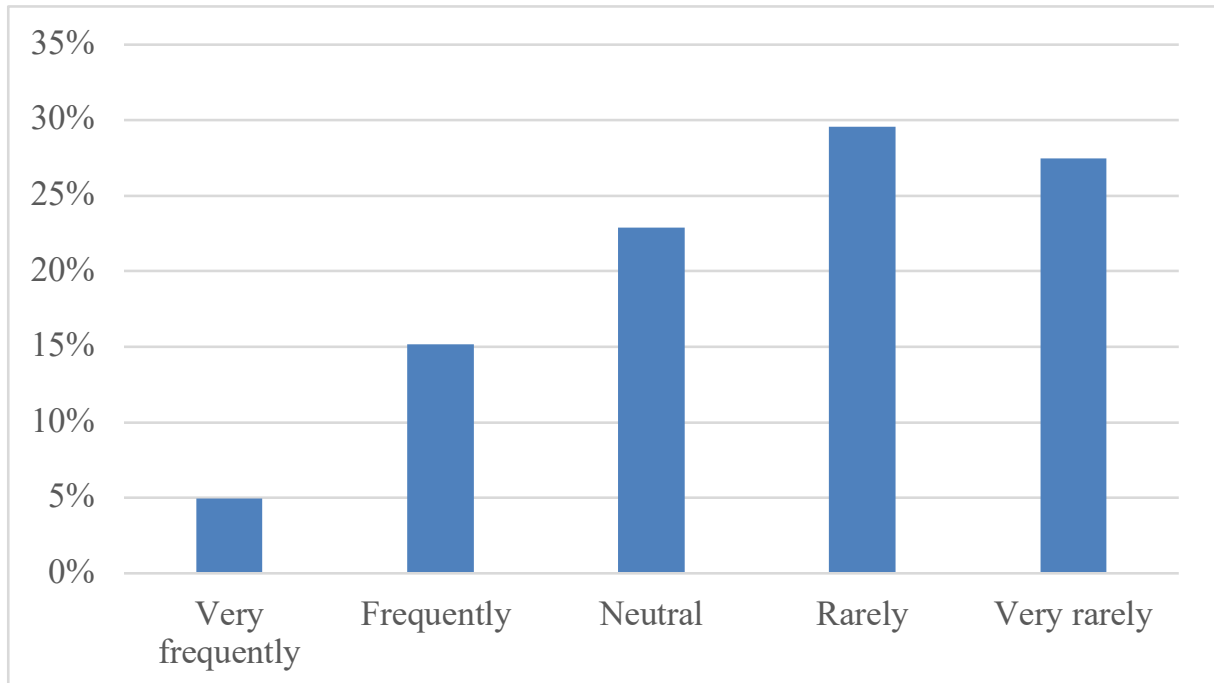

Figure 1: Average frequency of communication difficulties with multicultural students as perceived by teachers

According to respondents, on average, about 10 per cent of the multicultural students they had taught could not communicate with them because of limited Korean proficiency. Twenty-five teachers (17.6\%) reported having taught multicultural students who had very limited Korean language proficiency.

Despite language barriers, the results showed that when teachers encountered communication difficulties, they used various coping strategies to communicate directly with multicultural students despite their lack of Korean proficiency. Most respondents $(\mathrm{n}=105 ; 80.2 \%)$ indicated that they spoke slowly using simple words and expressions, $46(35.1 \%)$ used gestures and drawings to convey their messages, $13(9.9 \%)$ used foreign words students understood by finding translations in dictionaries and $10(7.6 \%)$ used translation apps and machine translation programs such as Google Translate and Naver. Seven $(5.3 \%)$ relied on external resources, six (4.6\%) depended on other students and five $(3.8 \%)$ on other parents for language assistance.

\subsubsection{Teachers' experience of communication with migrant parents}

While it appears that the teachers experienced communication problems with migrant parents slightly more frequently in comparison to multicultural students, nearly half of teachers indicated that they did not experience great difficulties 
in communication with migrant parents (see Figure 2). Of the surveyed teachers, $48(33.8 \%)$ indicated they rarely had difficulties and $18(12.7 \%)$ very rarely, whereas five (3.5\%) and $31(21.8 \%)$ responded that they had difficulties very frequently and frequently, respectively. Forty $(28.2 \%)$ respondents provided a neutral response to this question.

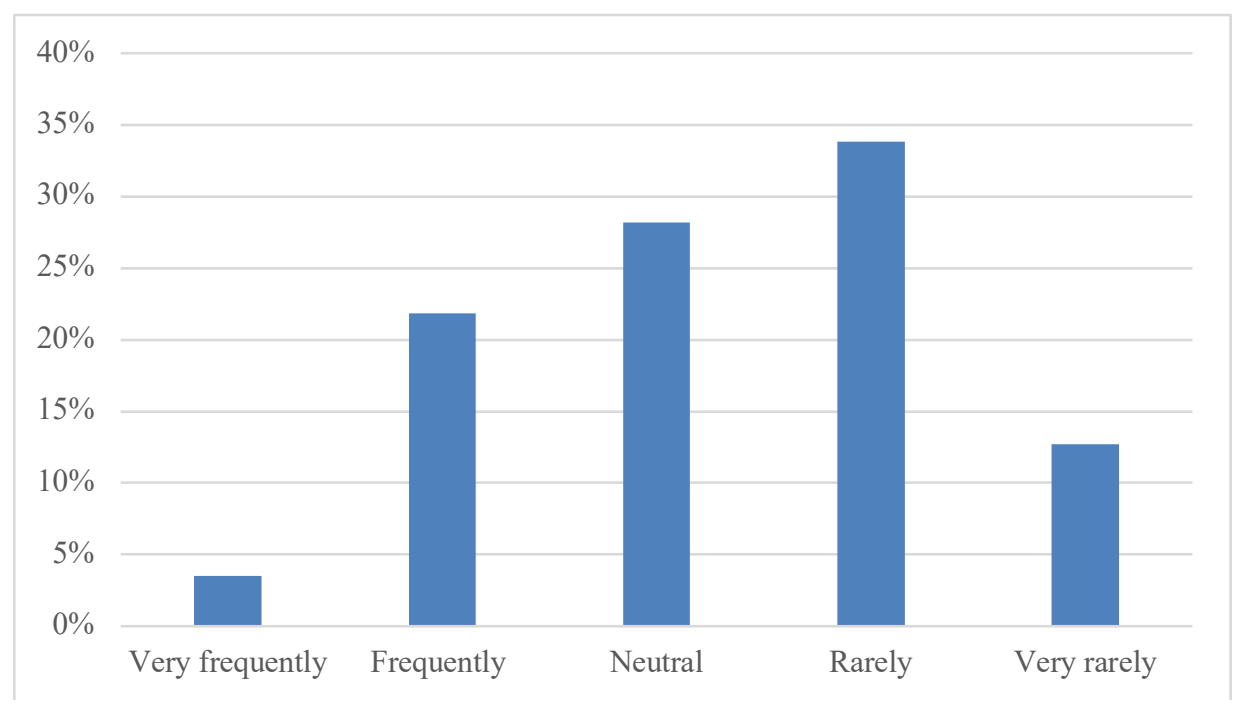

Figure 2: Average frequency of communication difficulties with migrant parents as perceived by teachers

Respondents with more experience teaching multicultural students also indicated experiencing difficulty in communicating with migrant parents more frequently. Of the eight teachers who taught 16 or more multicultural students over the past five years, three experienced communication difficulties frequently with migrant parents, predominantly mothers. Almost all respondents $(95.8 \%)$ said they had communication difficulties with migrant mothers, reflecting the demographic make-up of marriage migrants. Most respondents $(\mathrm{n}=54 ; 38.0 \%)$ believed that less than 10 per cent of migrant parents lacked the Korean language proficiency needed to communicate effectively in Korean, 20 respondents (14.1\%) chose 'between 10\% and 19\%', 19 (13.4\%) chose 'between 20\% and 29\%' and 14 (9.9\%) chose 'between 50\% and 59\%'. When combined, 31 (21.8\%) respondents believed more than half of migrant parents they had met had limited Korean proficiency.

More than one answer could be chosen for situations in which teachers experienced the most communication problems. Thus, most respondents $(\mathrm{n}=74$; $52.1 \%$ ) identified letter notices, namely delivery and response of written messages to parents, as the most frequent problem, highlighting the need for community translation services. Another 64 respondents (45.1\%) indicated that they experienced problems in face-to-face talks with parents, $53(37.3 \%)$ experienced issues providing information on homework and 28 (19.7\%) encountered issues with school event notices. Given that teachers do experience difficulties in both written and oral communication, both interpreting and translation services are necessary to help migrant parents understand the school curricula and school life of their children and play a supporting role in their children's school life.

The most frequently used mode of communication between teachers and migrant parents was phone conversations ( $\mathrm{n}=89 ; 62.7 \%)$, followed by face-toface communication $(\mathrm{n}=31 ; 21.8 \%)$ and social media (SNS) $(\mathrm{n}=17 ; 12.0 \%)$ (see 
Figure 3). No respondents chose email as a mode of communication. Interestingly, while the preferred mode of communication was phone conversations, migrant parents with limited Korean proficiency might not be comfortable talking with teachers on the phone without visual cues or the assistance of others.

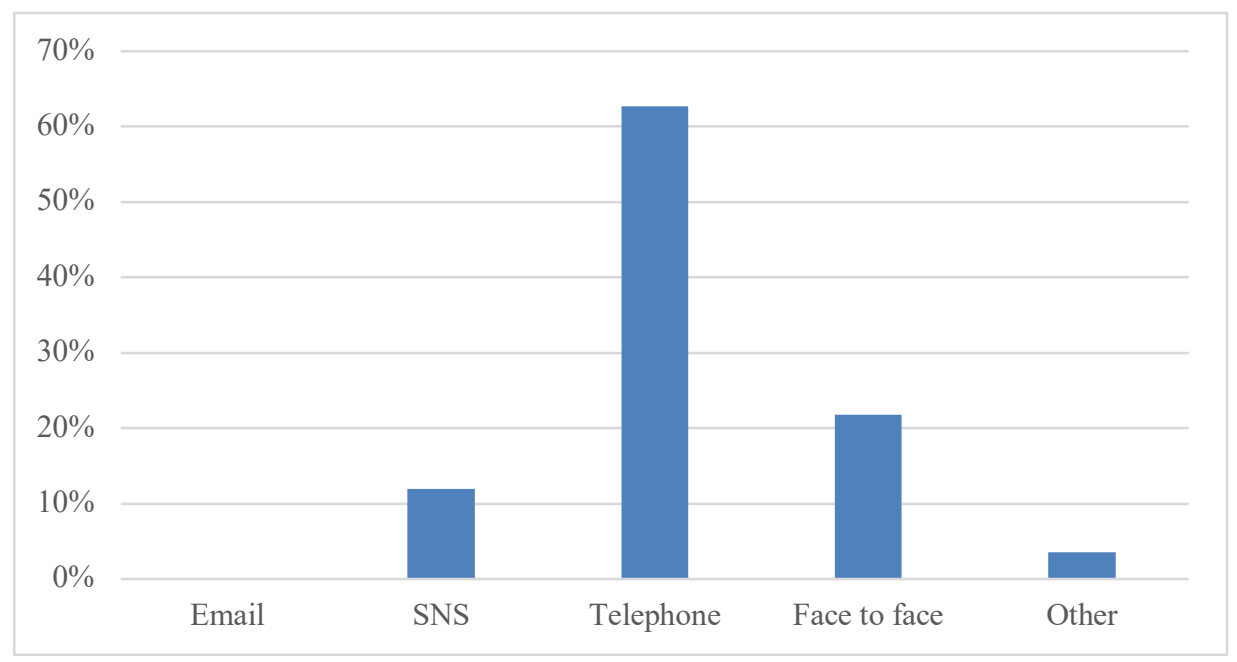

Figure 3: Mode of communication between teachers and migrant parents

Teachers had mixed views on the level of migrant parents' understanding of children's schooling and school life. Nearly 40 per cent of respondents thought migrant parents had little to very little knowledge on children's schooling and school life, $50(35.2 \%)$ believed parents' knowledge to be poor while six (4.2\%) thought migrant parent's knowledge was very poor. Approximately 30 per cent of respondents evaluated the level of migrant parents' knowledge positively: 40 (28.2\%) believing their knowledge to be fair and only four $(2.8 \%)$ indicating their knowledge to be very good. Another 42 (29.6\%) offered a neutral response to this question. More experienced teachers with greater exposure to multicultural students tended to have more negative perceptions about the multicultural parents' level of understanding and knowledge of schooling. Of the eight teachers who taught 16 or more multicultural students, five thought that migrant parents did not know about their children's schooling and school life, whereas one thought otherwise. Two offered a neutral response to the question.

The coping strategies employed by teachers when communicating with students and parents who lacked Korean proficiency were close to identical. Similar to the strategies used with students, respondents tended to communicate directly with migrant parents by speaking slowly and using simple words and expressions. Most respondents $(\mathrm{n}=105 ; 76.1 \%)$ indicated that it was their predominant coping strategy, while $31(22.5 \%)$ resorted to using gestures and drawing pictures when they faced language barriers. Eleven teachers $(8.0 \%)$ occasionally used foreign words migrant parents could understand, while nine respondents $(6.5 \%)$ used translation apps and machine translation programs such as Google Translate and Naver. Compared to teacher-student communication, the respondents relied more on third party help in communicating with parents who lacked Korean proficiency $(13.3 \%$ versus $20.4 \%)$. Another $11(8.0 \%)$ respondents relied on external resources, $10(7.3 \%)$ relied on other students' help and eight (5.8\%) asked for other parents' help when faced with difficulties in communicating with migrant parents. Fifteen 
(10.9\%) chose 'Other', but few specified what this entailed. Some teachers chose to talk to students' Korean-speaking grandparents or fathers instead of the mothers who lacked Korean proficiency. Exclusion of mothers may be the last resort for teachers, but should be avoided for the sake of parents' involvement. Non-Korean-speaking mothers can be involved if interpreting or language services are available.

Interestingly, teachers tended to attribute communication barriers to cultural differences. While only $12(8.5 \%)$ acknowledged having experienced miscommunication deriving from the lack language services provision, 32 respondents $(22.5 \%)$ reported having experienced significant cultural differences that could not be resolved during their interactions with migrant parents. Such cultural gaps were largely concerned with migrant parents' perceptions about their role in education and the roles of school, teachers and others. Because of the research methodology adopted for this study, it was not possible to further investigate these perceived cultural differences. It is also unclear whether such a gap in awareness was due to the parents' socioeconomic or cultural backgrounds. Further research can explore such cultural differences and the necessary cross-cultural mediation in educational interpreting.

Parent-teacher conversations covered sensitive matters, indicating that quality interpreting services are needed. A little over a quarter of respondents $(\mathrm{n}=37)$ indicated that they had talked about sensitive and private matters with migrant parents. Such topics included family life and home environment (66.7\%), peer relationships at school $(27.8 \%)$ and poor academic performance (25.0\%). Notably, of the teachers who addressed sensitive issues in their communication with migrant parents, $11(29.7 \%)$ received third party assistance. Apart from personal assistance from acquaintances, the most frequently used external language assistance was provided by local MFSCs and their affiliated Danuri Call Centre. The respondents' views on the language services received will be discussed in the following section.

\subsubsection{Teachers' experience of using language services and their opinions}

Perhaps being aware of the lack of language services available, teachers tended to manage on their own. Only 29 teachers $(20.4 \%)$ received language assistance from various sources, the MFSC and its affiliated call centre being the main language service providers. Ten respondents used the MFSC service and one used the affiliated call centre. A smaller number of respondents also relied on bilingual education teachers associated with their schools, or the City Education Office. ${ }^{6}$ Eighteen teachers received language assistance from other sources, including personal acquaintances, parents or colleagues. None chose BBB Korea, which is a volunteer telephone interpreting service network. ${ }^{7}$ The results suggest that organised community interpreting services for teachers were not readily available.

\footnotetext{
${ }^{6}$ Bilingual education teachers, who are recruited from among female marriage migrants, support multicultural students' schooling through cultivation of their bilingual and bicultural competence. Like other employment opportunities created for marriage migrant women, the remuneration level is low and the job is not considered stable. Their main role is to offer after-school language lessons in both Korean and the mother tongues of multicultural students, and provide culture and foreign language classes to Korean students. They are also expected to provide language assistance for parentteacher meetings (J. B. Lee et al., 2010).

${ }^{7}$ www.bbbkorea.org
} 
The mode of language services teachers used was predominantly face-toface interpreting $(49.3 \%)$, followed by telephone interpreting $(27.6 \%)$ and translation $(10.3 \%)$. Respondents were generally satisfied with the language services they received, with 55.2 per cent finding it satisfactory or very satisfactory and 6.9 per cent finding it unsatisfactory or very unsatisfactory (see Figure 4). Thirty-seven per cent of respondents were neutral in their responses.

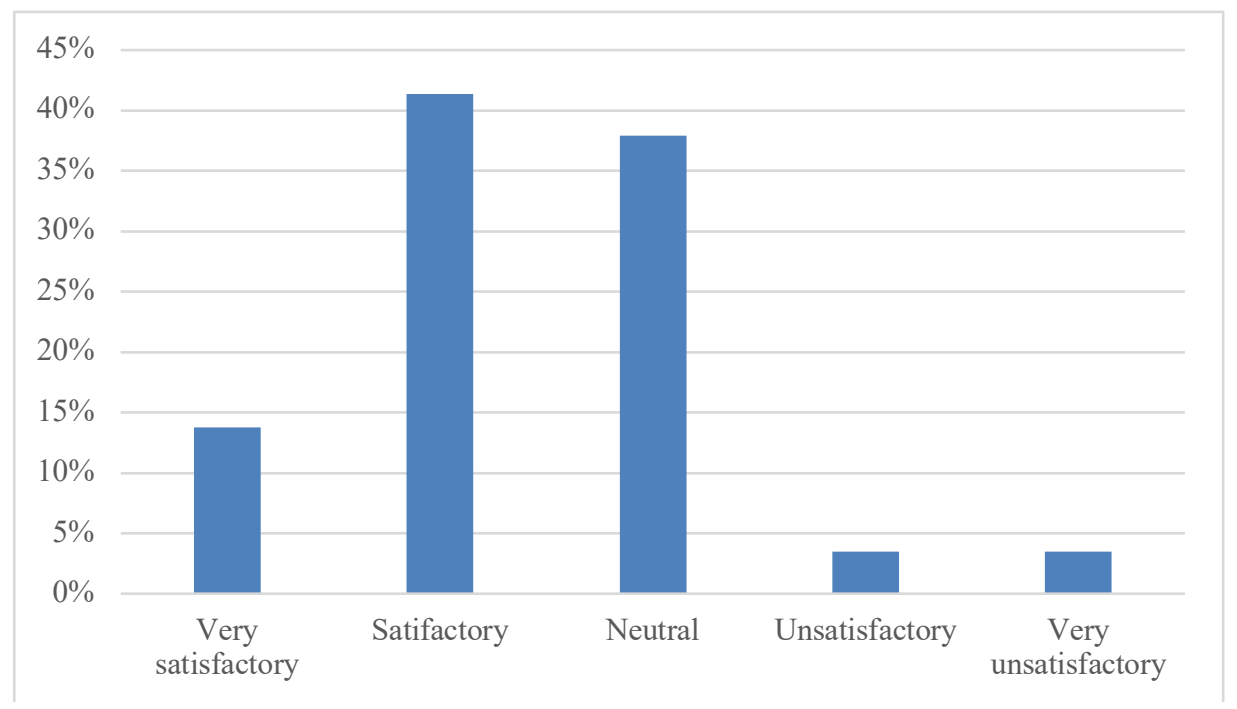

Figure 4: Perceived service quality

The responses suggest that the quality of interpreting might have been of little relevance in determining the level of respondents' satisfaction. Only two respondents cited interpreting and translation quality as the reason for their satisfaction, commenting that they were satisfied that such a provision was made and that it was better than nothing. Some commented that it enabled them to receive help in a timely manner. By contrast, some respondents found the services unhelpful partly because of the shortage and unavailability of language services. Others cited the inconvenience of accessing the service and service quality as the main reasons for their dissatisfaction. They commented that because of interpreters' lack of skills, they were restricted in conveying feelings across languages even though there was some level of linguistic mediation. The lack of availability of interpreters in the target language was also regarded as source of inconvenience. Some commented that the service was not sufficient given they were not able to resolve issues through one or two interpreted meetings because teaching and counselling should be ongoing processes.

When asked what they thought was the most effective mode of language services to assist multicultural students and their parents with school communication, most respondents $(\mathrm{n}=105 ; 73.9 \%)$ identified face-to-face interpreting, while 11 (11.97\%) chose telephone interpreting and 12 (8.45\%) chose interpreting and translation apps (see Figure 5). Notably, while respondents most frequently engaged in phone conversations with migrant parents, they found face-to-face language services to be the most effective mode of delivery. Although a dozen teachers found translation apps useful and handy, it is doubtful these translation apps can be relied on when the parent-teacher conversation moves beyond simple exchanges of information. 


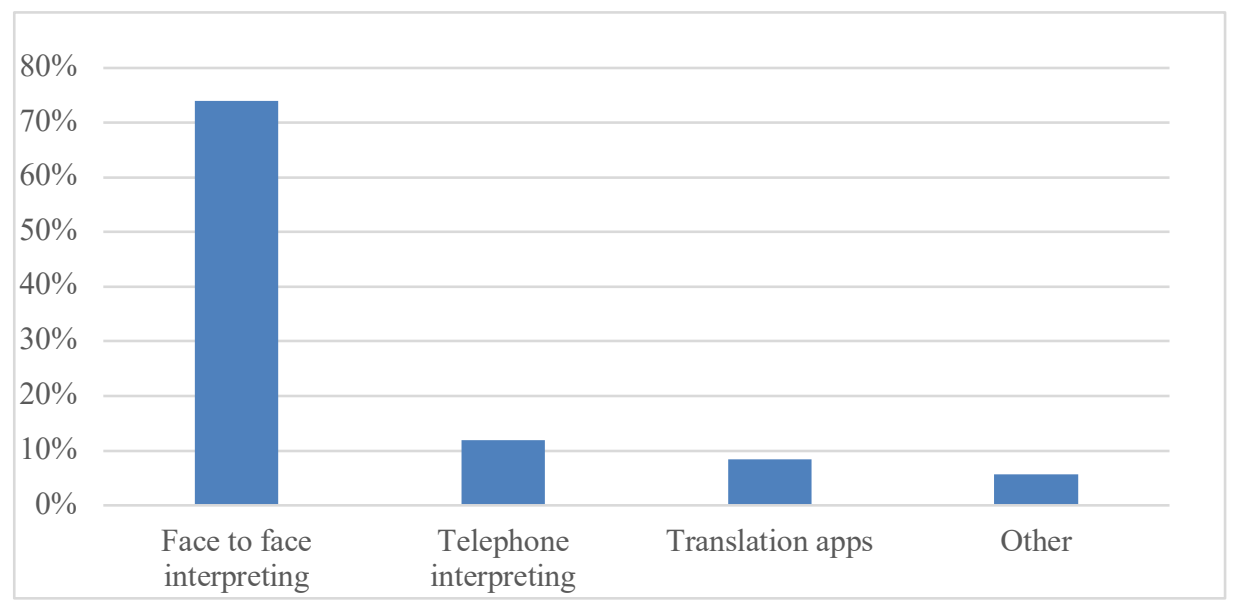

Figure 5: Effective mode of interpreting service

Most teachers agreed on the need for more effective language services in educational settings. Most respondents $(\mathrm{n}=114 ; 80.3 \%)$ supported more systematic and effective language services to facilitate teachers' communication with students and parents from migrant backgrounds. When they were invited to choose who would be the best person to provide language services in educational settings if costs did not matter, 59 (41.6\%) chose MFSC staff and 28 (19.7\%) chose bilingual education teachers, both of whom are currently the main providers of language services in educational settings. It may be because these providers are also marriage migrants and the respondents might have thought that migrant mothers may feel comfortable communicating through them. Twenty-six respondents $(8.3 \%)$ stated that it did not matter who provided the services. Only 18 respondents $(12.7 \%)$ chose professional interpreters and translators, possibly due to the teachers' awareness that professional interpreting and translation services in migrant languages were difficult to access.

Respondents could choose more than one answer regarding the competence of language service providers. They considered cross-cultural mediation competence as the most important requirement, with ninety-four $(66.2 \%)$ choosing this, while $74(52.1 \%)$ chose understanding of school education and $62(43.7 \%)$ chose an interest in students' education and welfare. Interpreting and translation skills were chosen by $40(28.2 \%)$ and came fourth among the six choices offered. The other two options, confidentiality and impartiality, which are key elements of professional interpreting, were chosen by $21(14.79 \%)$ and $14(9.86 \%)$ respondents, respectively. These results highlight teachers' lack of awareness of professional interpreting and its important ethical principles as well as their view that just interpreting is not sufficient in educational interpreting.

\subsubsection{Teachers' comments}

At the end of the survey, respondents were invited to comment on ways to facilitate communication between teachers and multicultural families. However, only 20 per cent of respondents left brief comments stressing that education for students and parents was needed to help them overcome cultural and linguistic differences. This was in line with the focus of the current South Korean language policy for multicultural families (Kim, 2008; Kang, 2013; Lee \& Kim, 2016). Teachers commented: 
The top priority should be providing assistance for teachers and parents to learn the language. ( $\mathrm{T} 22$ )

Korean education should be provided for multicultural families before their children reach school age. For students who do not speak the language of instruction, interpreting and translation for home-school communication is necessary on a regular basis. ( $\mathrm{T} 1$ )

Ongoing language and culture training should be provided for new multicultural families. (T 36)

One teacher even commented that parents should learn Korean before their children reach school age, reflecting a somewhat nationalistic and discriminatory attitude. Some suggested joint training for raising awareness of cultural differences, while others emphasised that native Korean fathers of multicultural students should be more actively involved:

A joint training in which mainstream students, multicultural students and their parents participate together may help to expand mutual understanding. (T 30)

It is important to raise awareness of (Korean-born) fathers of multicultural students because they can play important roles in their children's schooling. MFSC should offer training for fathers to better understand their children and their spouses from different cultural backgrounds. (T 10)

In addition to parents' education for Korean language skill acquisition, some recommended teacher training for foreign language learning and cultural awareness:

Teacher training on multiculturalism is needed. (T 2)

Teachers need to build their capacity to speak a foreign language and to better understand students' linguistic and cultural backgrounds. (T 32)

Teachers' comments also confirmed their lack of interest in professional language services. This might be attributed to the respondents' limited experience with these services, or, more likely, because respondents were aware that there were not enough resources to hire professional language service providers. One respondent somewhat naively commented that machine translation or automatic translation would solve the problem. Such an overreliance on machine translation revealed that respondents were not acutely aware of the limitations of translation apps or machine translation software available, and the complexity of communication across languages and cultures. Some respondents suggested setting up a system that could mobilise existing resources efficiently. They expected the City Education Office or the MFSCs to play more active roles in language service provisions. It is not clear who bears the responsibility for resolving communication difficulties in educational settings among the respective schools: the local Education Office, the MOE, the Ministry of Gender Equality and Family, which oversees the MFSC, or all of the above. As different government ministries and agencies are involved in the delivery of services for multicultural families, a more coordinated approach is required to fill the gap in the service delivery:

Because individual schools do not have the resources to cater to the needs of language services, City Education Offices should take the lead in establishing an infrastructure for interpreting services available in the city. (T 13) 
Multicultural Family Support Centre staff should be readily available for language services. (T 12)

There are quite a lot of letters sent home, and some of them are routine communication circulated at around the same time. If Multicultural Family Support Centres run a webpage with the gist of common letters, it would help parents' understanding. I think translation of essential information is desirable. (T 20)

Some suggested mobilising existing human resources, namely bilingual education teachers:

Bilingual education teachers should support students at school and teach Korean language and culture to parents. (T 29)

Under the current circumstances, bilingual education teachers' roles and the scope of their professional capacity may be limited. They lack professional interpreting and translation training, even more so than MFSC bilingual staff, whose main role is to provide language services. However, since they are already working in schools contractually, they might be well positioned to effectively facilitate communication within school and between home and school with additional training.

\section{Discussion and conclusion}

Using a questionnaire-based survey of 142 Korean elementary schoolteachers, the study reported on here sought to investigate the current situation of communication between elementary schoolteachers and both students and parents from migrant backgrounds in the South Korean city of Busan. The results demonstrated that elementary schoolteachers often had difficulties communicating with both students and parents from migrant backgrounds. However, there was a lack of organised language services to facilitate the communication between school and home and also with students within the school. The findings indicated that teachers had limited experience in using language services other than ad-hoc assistance offered by bilingual students, migrant parents or their acquaintances. In the absence of readily available language services, teachers tended to manage on their own or relied on ad-hoc solutions that might actually hamper effective communication. Only one-fifth of respondents used third-party language services.

While teachers were found to be supportive of systematic language services in educational settings, they stressed the importance of Korean language acquisition, echoing the current government policy of social integration. Despite the overall support and palpable need for language services in educational interpreting, there was consensus among the teachers that fast, complete adaptation and integration of marriage migrants and their children into Korean society is a priority of South Korean multicultural family policy (Kim \& Kilkey, 2016, p. 146).

This paper has some limitations. The findings from this survey are based on a small group of elementary schoolteachers and can therefore not be generalised to the entire population. It was not possibly to elicit detailed responses on teachers' perspectives from survey responses. Qualitative approaches examining the views of teachers, multicultural students and migrant parents from broader regions or exploring actual interactions in diverse 
educational settings may provide further insight into the issue. Given the gap in the literature on educational interpreting, further research is necessary to gain further understanding of the skills and knowledge needed in performing the role of interpreter in educational settings. The work of educational interpreters is not simple, as they need to consider many factors, including the needs of each situation, students and parents on an ongoing basis to facilitate students' learning and enhance opportunities for participation by students and their parents (Smith, 2015, p. 274). The teachers considered cultural mediation to be an important factor in educational interpreting, which strongly suggests that interpreters working in educational settings should be equipped with appropriate skills to mediate cross-cultural communication. To facilitate crosslinguistic and cross-cultural communication in educational settings, both mediation and interpreting skills are desirable (Foulquié Rubio \& Abril Martí, 2013). This paper did not attempt to debate the distinction between interpreting and cultural mediation. Thus, future research may investigate what would constitute best service in a local context.

For better partnership that supports the education of children from diverse cultural and linguistic backgrounds, students, teachers and migrant parents should be engaged in unconstrained communication, both spoken and written, with the assistance of quality language services offered by trained professionals. More coordinated efforts from relevant government institutions are required to provide practical assistance to improve communication between schools and multicultural families. The national and local governments need to consider increasing investment in training and employing bilingual human resources in this setting. Moreover, language service providers should be upskilled to acquire professional-level skills in interpreting, translation and cross-cultural mediation. Also, by building on the existing service networks for multicultural families, the government can establish more effective and readily available language services that serve the interest of multicultural families and support the education of multicultural students. In either case, proper training that combines interpreting and translation skills with interpersonal and crosscultural mediation is needed.

\section{Acknowledgement}

I would like to thank the anonymous reviewers who have provided thoughtful comments and suggestions. I am also grateful to Vice Principal Mr. Kim Taekyong at Busan Baekyang Elementary School, without whom it would not have been possible to conduct the survey-based research.

\section{References}

Adelsward, V. \& Nilholm, C. (1998). Discourse about children with mental disablement: An analysis of teacher-parent conferences in special education schools. Language and Education, 12 (2), 81-98.

Angelelli, C. (2010). A professional ideology in the making: Bilingual youngsters interpreting for their communities and the notion of (no) choice. Translation and Interpreting Studies, 5(1), 94-108.

Bae, S. S. \& Suh, M. O. (2013). Kyengpwukciyek tamwunhwakacenguy haklyengki canyekyoyuk silthay: canyekyoyukeyse sahoykyengceycek ciwiuy yenghyangul cwungsimulo (The status of multicultural school-age Children`s education in gyeongbuk province). Chotungtotekkyoyuk, 43, 195-224.

Baraldi, C. (2009). Forms of mediation. Language and Intercultural Communication, 9(2), 120-137. 
Borrero, N. (2011). Nurturing students' strengths: The impact of a school-based student interpreter program on Latino/a students' reading comprehension and English language development. Urban Education, 46(4), 663-688.

Bullock, C. \& Harris, B. (1997). Schoolchildren as community interpreters. In S. Carr et al. (Eds.), The critical link: interpreters in the community. (pp.227-235) Amsterdam: John Benjamins.

Buriel, R., Perez, W., DeMent, L., Chavez, D., \& Moran, V. (1998). The relationship of language brokering to academic performance, biculturalism and self-efficacy among Latino adolescents. Hispanic Journal of Behavioral Sciences, 20, 283-297.

Bush, B. R. A. \& Folger, J. P. (1994). The promise of mediation: Responding to conflict through empowerment and recognition. San Francisco: Jossey-Bass.

Cheon, H.-S. \& Park, G.-S. (2012). Tamwunhwakaceng canyeuy hakkyosaynghwaley kwanhan yenkwu (A study on the school life of children of multicultural families). Hyentaysahoywatamwunhwa, 2(2), 415-442.

Choi, H. W. \& Hwang, B. M. (2009). Tamwunhwakaceng icwuyesenguy hankwukenunglyeki canyeuy hankwukenunglyek paltaley michinun yenghyang (A effects of Mother's Korean abilities on their Children's Korean abilities in multi-cultural family). Ilonkwa silchen, 10(4), 315-329.

Chung, H. S., Kim, Y. S., Yi, T. Ma, K. H. Choi, G., Park, C. Tong, J. Hwang, J, \& Lee, E. (2016). 2015nyen cenkwuktamwunhwakacok siltaycosa (2015 national survey of multicultural families). Seoul: KWDI.

Davitti, E. (2013). Dialogue interpreting as intercultural mediation: Interpreters' use of upgrading moves in parent-teaching meetings. Interpreting, 15(2), 168-199.

Foulquié Rubio, A. I. \& Abril Martí, I (2013). The role of the interpreter in educational settings: Interpreter, cultural mediator or both?. In C. Schäffner, K. Kredens \& Y. Fowler (Eds.), Interpreting in a changing landscape: Selected papers from Critical Link 6 (pp. 203-221). Amsterdam, Netherlands: John Benjamins.

Hall, N. (2004). The child in the middle: Agency and diplomacy in language brokering events. In G. Hansen, K., Malmkjaer, \& D. Gile (Eds.), Claims, changes and challenges in translation studies. Amsterdam: John Benjamins.

Han, J. S. \& Kim, H. S. (2011). Nongchon kwukceykyelhonkaceng chotunghaksaynguy kyoyuk mwuncey (An analysis of the problem of education for children from international marriage families in agricultural region). Paywumhakyenkwu, 3(1), 49-60.

Hlavac, J. (2017). Brokers, dual-role mediators and professional interpreters: a discourse-based examination of mediated speech and the roles that linguistic mediators enact. The Translator, 23(2), 197-216. doi: 10.1080/13556509.2017. 1323071

Hwang, J. (2016). Wulinala tamwunhwahaksayng hyenhwang (The current status of multicultural students) Education Development, 197. http://kess.kedi.re.kr/post/ 6656386? itemCode $=03 \&$ menuId $=$ m_02_03_02

Hwang, M., Gao, H. \& Kim, J. (2010). Chotungkyosauy tamwunhwakaceng atong cito kyenghem (Experiences of elementary school teachers with ethnic minorities' children). Asiakyoyukyenkwu, 11(1), 147-167.

Hwang, S. (2019). Tamwunhwaatonguy icwungenesayongkwa kyoyuk sepisu ceykongeyse thongyeksa hyeplyekey kwanhan yenkwu (Dual language use of children with culturally and linguistically diverse backgrounds and interpreter cooperation during service delivery in Korea). Enechilyoyenkwu, 28(1), 37-46.

Kang, J.- H. (2013). Tamwunhwasahoy tamloneyse thongyekuy yekhal yenkwu (Community interpreting in discourses of multiculturalism.) Penyekhakyenkwu, 14(5), 7-41.

Kim H. S. (2008). Kyelhonicwuyesengkwa hankwukuy tamwunhwasahouy silhemchoykun tamwunhwatamlonuy sahoyhak (Migrant brides and making of a multicultural society: Sociological approach to recent discourse on "Multicultural Korea"). Hankwuksahoyhak, 42(2), 36-71.

Kim, E. Y. \& Lee, K. Y. (2016). Chocwungko hakpwumowa hakkyouy sothong silthay mich hwalsenghwa pangan yenkwu: hakpwumo hakkyochamye sipemhakkyolul cwungsimulo (Study on actual condition and activation of the communication between school and parents by parents of elementary, middle, and high school

Translation \& Interpreting Vol. 13 No. 1 (2021) 
students: Focusing on parent involvement model schools). Haksupcacwungsimkyokwakyoyukyenkwu, 16 (7), 27-49.

Kim, G. \& Kilkey, M. (2016). Marriage migration policy as a social reproduction system: The South Korean experience. In M. Kilkey \& E. Palenga-Mollenbeck (Eds.), Family life in an age of migration and mobility: Global perspectives through the life course (pp.137-172). London: Palgrave Macmillan.

Lee, J., Chang, A. Choi, M. \& Huh, J. (2014b). Hankwuknay oykwukinul wihan thongyek sepisu hyenhwangey kwanhan soko (A study of community interpreting for foreigners in Korea). Thongpenyekhakyenkwu, 18(4), 167-191.

Lee, J., Chang, A., Choi, M. \& Huh, J. (2014a). Kyelhoniminca thongpenyeksepisu saepul thonghay pon ciyeksahoy thongyek (A case study of T\&I services for marriage migrants and multicultural families). Penyekhakyenkwu, 15(3), 177-210.

Lee, J., Choi, M. Huh, J. \& Chang, A. (2016). Community interpreting services by marriage migrants for marriage migrants in South Korea. Perspectives, 24(2), 179-200, doi: 10.1080/0907676X.2015.1052524.

Lee, J., Choi, M., Chang, A. \& Huh, J. (2015). Kyelhoniminca thongpenyeksepisu centaminlyek salyeyyenkwu (Recommendations for the Training of Community Interpreting in the Context of Marriage Migrant T\&I Services.) Penyekhakyenkwu, 16(3), 197-228.

Lee, J. B., Kim, H. \& Oh, S. B. (2009). Hakkyoeyseuy tamwunhwakacok kyoyukciwen silthay mich yokwucosa (Investigation of current status and needs of educational support for multicultural families at school). Seoul: Korean Educational Development Institute.

Lee. J. B., Park, K., Kim, K. S., Kim, S. \& Kim S. Y. (2010). Tamwunhwakacok canyeuy kyelhonimin pwumo chwulsinkwuk enesuptukul wihan kyoyuk ciwen salyeyyenkwu (A Case Study on Learning the Mother Tongue: Children Born from Multicultural Parents Residing in Korea). Seoul: KWDI/KEDI.

Lee, S. \& Kim, W. (2016). Tamwunhwakaceng canye kyoyukey tayhan emeniwa kyosauy insik (Culturally and linguistically diverse mothers' and teachers' perceptions on Children's education of the mothers). Thukswuatongkyoyukyenkwu, 18(3), 119-141.

Leung, P. \& Yuen, M. (2001). Parent-teacher conference in a secondary school: A case study. Pastoral Care in Education, 19 (1), 28-30.

McQuillan, J., \& Tse, L. (1995). Child language brokering in linguistic minority communities: Effects on cultural interaction, cognition and literacy. Language and Education, 9, 195-215.

Mikkelson, H. (2014). Evolution of public service interpreter training in the U.S. Public Service Interpreting \& Translation, 1(1), 1-22.

Ministry of Education (MOE) (2017). 2017 Education basic statistics summary. http://kess.kedi.re.kr/index

Ministry of the Interior and Safety (MOIS) (2017). Local governments' foreign residents survey results. http://www.mois.go.kr/frt/bbs/type001/commonSelect BoardArticle.do?bbsId=BBSMSTR 000000000014\&nttId=60528

Morales, A. \& Hanson, W. (2005). Language brokering: An integrative review of the literature. Hisp. J. Behav. Sci., 27(4), 471-503.

Nam, B. H. \& Kim, O. N. (2012). Yesengkyelhonimincauy hakpwumo yekhaley tayhan cilcek yenkwu: swutokwenuy kohaklyekyesengul cwungsimulo (A qualitative study on the experiences of marriage immigrant women as school parents). Chengsonyenpokciyenkwu, 14(4), 113-142.

$\mathrm{Ng}$, J. (1998). From kitchen to classroom: Reflections of a language broker. Voices from the Middle, 6(1), 38-40.

Park, J. (2011). Cwungtoipkwuk tamwunhwakaceng canyelul wihan thongyek pocokyosaceyey tayhan ceyen (Proposals for the interpretation assistant teacher system for the immigrant children of multicultural families). Ihwaenenoncip, 29, $103-125$.

Ragavan, M. I. and Cowden, J. D. (2018). The complexities of assessing language and interpreter preferences in pediatrics. Health Inquiry, 2(1), 70-73.

Rudvin, M. \& Tomassini, E. (2008). Migration, ideology and the interpreter-mediator. The role of the language mediator in educational and medical settings in Italy. In

Translation \& Interpreting Vol. 13 No. 1 (2021) 
C. Valero Garcés \& A. Martin (Eds.), Crossing borders in community interpreting: Definitions and dilemmas (pp. 245-266). Amsterdam \& Philadelphia: John Benjamins.

Sanders, M. G. \& Epstein, J. L. (2000). Building school-family-community partnerships in middle and high School. In M. G. Sanders (Ed.), School students placed at risk: Research, policy, and practice in the education of poor and minority adolescents (pp.339-362). Mahwah: Erlbaum.

Shackman, J. (1984). The right to be understood: A handbook on working with, employing and training community interpreters. London: National Extension College.

Smith, M. B. (2013). More than meets the eye: Revealing the complexities of an interpreted education. Washington DC: Gallaudet University Press.

Smith, M. B. (2015). Interpreting in education. In H. Mikkelson \& R. Jourdenais (Eds.), Routledge handbook of interpreting (pp. 265-279). London / New York: Routledge.

Tipton, R. and Furmanek, O. (2016). Dialogue interpreting: A guide to interpreting in public services and the community. London: Routledge.

Tse, L. (1995). Language brokering among Latino adolescents: Prevalence, attitudes, and school performance. Hispanic Journal of Behavioral Sciences, 17, 180-193.

Vargas-Urpi, M. (2015). Dialogue interpreting in multi-party encounters: two examples from educational settings. Interpreters' Newsletter, 20, 107-121.

Victorian Government (n.d.). Using interpreting services: Victorian government guidelines on policy and procedures. Retrieved 21 February 2020 from https://www.vic.gov.au/guidelines-using-interpreting-services/understandinglanguage-services.

Weisskirch, R. S., \& Alva-Alatorre, S. (2002). Language brokering and the acculturation of Latino/a students. Hispanic Journal of Behavioral Sciences, 24, 369-378.

Xu, Z. \& Gulosino, C. A. (2006). How does teacher quality matter?: The effect of teacher-parent partnership on early childhood performance in public and private schools. Education Economics, 14(3), 345-367.

Yang, H. (2013). Kacok anulo tuleon hankwukuy tamwunhwacwuuy silhem (Experiment of "the Multiculturalism" in Korea Taking Place in the Family). Justice, 134(2), 298-335. 